\title{
Could the Production of Green Agricultural Products Increase Farmer Household Income? - An Empirical Analysis on Farmer Households in Inner Mongolia Autonomous Region
}

\author{
Zhijuan Liu, Yuanfeng Zhao* \\ College of Economics and Management, Inner Mongolia Agricultural University, Hohhot 010019, China
}

Corresponding Author Email: liuzhijuan@emails.imau.edu.cn

https://doi.org/10.18280/ijsdp.150204

Received: 10 May 2019

Accepted: 5 January 2020

\section{Keywords:}

agricultural products (APs), green APs production, farmer household income, additional benefits, model of treatment effects

\begin{abstract}
To achieve high-quality development of agriculture, it is important to improve quality and increase benefits. The quality of agriculture can be improved through the production of green agricultural products (APs). However, the key to achieving high-quality development of agriculture is to increase benefits, i.e. increase the income of farmer household, through the production of green APs. To judge whether green APs production could boost farmer household income, this paper collects data from questionnaire survey on farmer households in northern China's Inner Mongolia Autonomous Region (IMAR), and assesses the impact of green APs production on farmer household income by descriptive analysis and the model of treatment effects. The results show that green APs production had a significant positive impact on the net mean income per mu of farmer households in crop farming, i.e. green APs production obviously promotes farmer household income. The research findings help to promote green production of farmer households and achieve high-quality development of agriculture.
\end{abstract}

\section{INTRODUCTION}

High-quality development is essential to modern agriculture. To achieve high-quality development of agriculture, it is important to improve quality and increase benefits. Currently, agricultural production faces with two major problems: the worsening eco-environment and the unstable quality of agricultural products (APs). Against this backdrop, the production mode must be changed to develop agriculture in a high-quality manner, highlighting the quality and greenness of APs [1].

Green APs refer to non-toxic, harmless, and high-quality APs, which are produced by specific techniques/processes and approved by certification bodies to use the "Green APs" label $[2,3]$. Typical green APs include pollution-free APs, green foods and organic APs. The greening of APs production helps to enhance the quality of APs, making it possible to improve the quality of agriculture. However, the key to achieving highquality development of agriculture is to increase benefits, i.e. increase the income of farmer household, through the production of green APs.

To realize high-quality development of agriculture, it is highly necessary to analyze the realistic impact of green APs production on farmer household income. The analysis results could reflect how green APs production influences farmer household income, and guide individual farmer households to green their production.

Many scholars have studied whether green APs production could increase farmer household income. Some scholars gave a negative answer, for some farmer households are crowded out by the high input and low output of green APs production [4-6]. Meanwhile, most scholars argued that the benefits of farmer households from green APs production are greatly affected by product prices; since the high-quality of green APs brings good prices [7], green APs production could definitely increase farmer household income [8-13].

Through case analysis, Vasile et al. [14] concluded that the production of organic APs creates slightly higher economic benefits than that of ordinary Aps. Based on the survey of farmer households in Nakuru, Bett et al. [15] constructed a spreadsheet model to analyze the effect of green APs production on farmer household income, and found that organic farmer households achieved higher benefits of net present value than others. Qiao et al. [16] conducted a questionnaire survey among organic farmer households in Wanzai County, Jiangxi Province, China, and discussed the impact of organic APs production on farmer household income through variance analysis and multiple comparisons, revealing that organic APs production pushes up the income of small farmer households. With the aid of propensity score matching (PSM), Doanh et al. [17] assessed the impact of organic tea production on farmer household income in Thailand, and demonstrated the positive effect of organic tea production on household agricultural income in the study area: each household received 202,000VND more benefits per hectare.

The above studies show that green APs production offers farmer households a desirable way to maximize benefits, providing a useful reference for our research. However, there are two main defects with the existing research. First, the relevant research falls short in empirical evidences, and the few empirical analyses lack reliable theoretical support. Second, most scholars have ignored the sampling bias, which arises from the endogeneity of unobserved variables or the production of green APs (Yes/No).

The Inner Mongolia Autonomous Region (IMAR) is the 
main producing area of APs in China. The IMAR boasts natural advantages in green APs production, including but not limited to an abundance of natural resources, an ample space for development, and a large environmental capacity. In 2019, the IMAR produced a total of 36.53 million tons, ranking the eighth among all provincial administrative regions (hereinafter referred to as provinces) of China. Besides, the IMAR is irrefutably the most important production base of green APs in China [18]. In the IMAR, 1,222 enterprises produced 3,623 different types of APs with green, organic and geographical indications. The weight of such APs totaled more than 14 million tons, more than that of any other province.

As the main operators of agricultural production, farmer households have the right to decide whether to produce green APs. To judge whether green APs production could boost farmer household income, this paper collects data from questionnaire survey on farmer households, and assesses the impact of green APs production on farmer household income through theoretical analysis and statistical comparisons. Moreover, the endogeneity of unobserved variables or the production of green APs (Yes/No) was fully considered and solved, and the impact of green APs production on farmer household income was verified through empirical analysis. The research results facilitate the formulation of targeted policies on green APs production, and help to increase farmer household income.

The remainder of this paper is organized as follows: Section 2 theoretically analyzes the impact of green APs production on farmer household income, and puts forward a hypothesis; Section 3 introduces the research methods and data source, and describes the hypothesis statistically through comparative analyses; Section 4 further validates the proposed hypothesis with an empirical model, and tests the robustness of the model results; Section 5 draws the conclusions and makes policy recommendations.

\section{THEORETICAL ANALYSIS AND HYPOTHESIS}

In market economy, each farmer household is a rational economic man. The most important goal for the household to engage in agricultural production is to pursue the maximal profit [19]. On a voluntary basis, a farmer household prefers to produce green APs, if green APs production brings more benefits than ordinary APs production.

The previous studies have shown that green APs production can increase farmer household income. Therefore, this paper puts forward the following hypothesis:

$\mathrm{H}$ : Green APs production can increase farmer household income.

The above hypothesis only holds under certain conditions. Below is an analysis on these conditions.

To make the incomes of different farmer households comparable, the profit of a farmer household through APs production was defined as the mean net income per mu of crop farming, i.e. the difference between the mean benefit per mu and the mean cost per mu. Then, the net mean income for a farmer household to produce $m$ types of green APs or ordinary APs $\left(\pi_{g}\right.$ or $\left.\pi_{o}\right)$ can be respectively expressed as:

$$
\pi_{g}=\sum_{i=1}^{m} p_{g} q_{g}-\sum_{i=1}^{\mathrm{m}} c_{g}, \pi_{o}=\sum_{i=1}^{m} p_{o} q_{o}-\sum_{i=1}^{\mathrm{m}} c_{o}
$$

where, $p, q$ and $c$ are the price per half a kilo, the mean yield per mu, and the mean cost per mu of APs, respectively.

Next, the net mean income for farmer households to produce green APs or ordinary APs was plotted as Figure 1 according to the following economic principles:
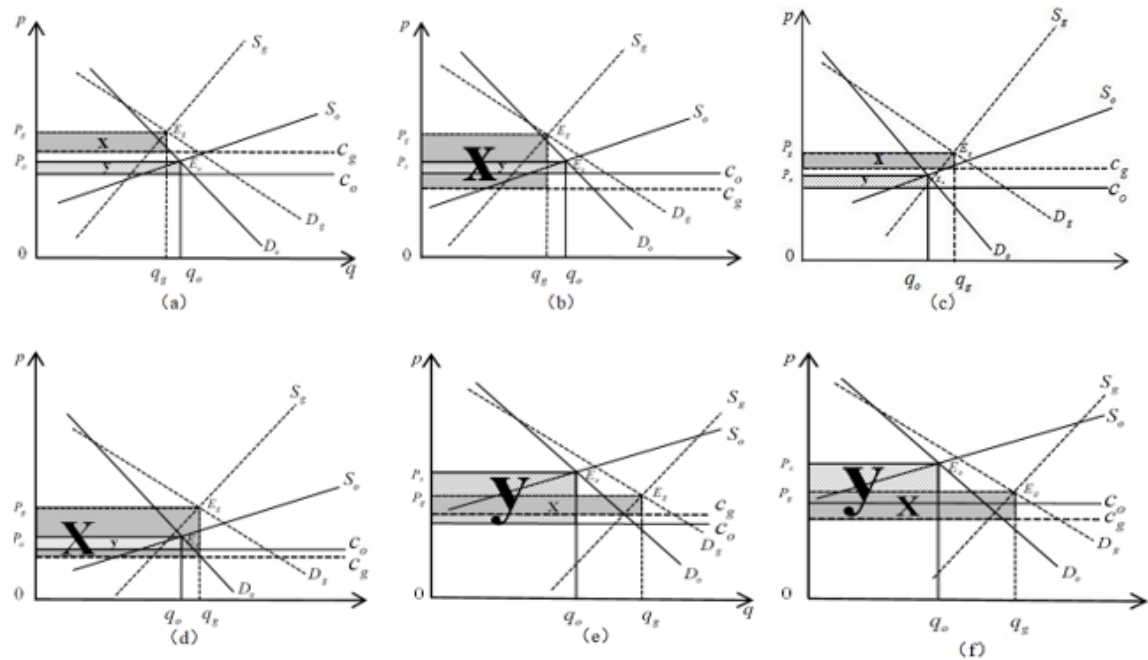

Figure 1. The net mean income for a household to produce green APs or ordinary APs

The price hike or price drop has little impact on the supply of green APs, due to the strict production standards and complex certification processes of such products. In other words, the supply of green APs is insensitive to price variation. The insensitivity indicates that the supply of green APs is inelastic, i.e. the supply curve of green APs is steeper than that of ordinary APs. However, any rise or fall of green APs price will cause a large increase or decrease in consumer demand for such products, i.e. the product demand is highly elastic.
Therefore, the demand curve of green APs is gentler than that of ordinary APs.

In Figure $1, S$ and $D$ are supply and demand curves, respectively; $E$ is the equilibrium point between supply and demand; $P$ and $q$ are the equilibrium price and yield, respectively. To calculate the net mean income per mu, the cost curve $\mathrm{c}$ was added to the figure, assuming that the cost is constant. Then, the shaded areas $x$ and $y$ are the net mean incomes per mu of green APs and ordinary APs, respectively. 
The relationships between price $p$ and yield $q$ of green and ordinary APs can be described as:

$$
\left\{\begin{array}{l}
\mathrm{p}_{g}>p_{o}, q_{g}<q_{o} \cdots(\mathrm{a}, \mathrm{b}) \\
\mathrm{p}_{g}>p_{o}, q_{g}>q_{o} \cdots(\mathrm{c}, \mathrm{d}) \\
\mathrm{p}_{g}<p_{o}, q_{g}>q_{o} \cdots(\mathrm{e}, \mathrm{f})
\end{array}\right.
$$

Since the cost $c$ is assumed, the cost of green APs should be compared with that of ordinary APs by formula (2). Considering the similarity between Figures (a, b), (c, d) and (e, f) in cost comparison, formula (2) $(\mathrm{a}, \mathrm{b})$ was cited as an example. If our hypothesis holds, then the net mean income per mu $x$ of a type of green APs must be greater than that $y$ of ordinary APs in the same type. This inequality can be described as $\left(p_{g}-c_{g}\right) q_{g}>\left(p_{0}-c_{0}\right) q_{0}$. Formula (2) (a, b) shows that $q_{0}>q_{g}$, i.e. $q_{0} q_{g}>1$. Then, $\left(p_{g}-c_{g}\right) q_{g}>\left(p_{0}-c_{0}\right) q_{0}$ can be converted to $\left(p_{g}-c_{g}\right) /\left(p_{0}-c_{0}\right)>1$, i.e. $p_{g}-c_{g}>p_{0}-c_{0}$; whereas $p_{g}>p_{0}$, i.e. $p_{g}-p_{0}>0$, we have $c_{g}-c_{0}>0$ or $c_{g}-c_{0}<0$. Finally, it is concluded that $c_{g}>c_{0}$ or $c_{g}<c_{0}$.

To sum up, theoretical analysis shows that green APs production can increase farmer household income, if and only if one of the following conditions is satisfied:

(1) The green APs have a higher price, lower yield and higher cost than ordinary APs: $p_{g}>p_{0}, q_{g}<q_{0}$, and $c_{g}>c_{0}$ (Figure $1 \mathrm{a})$;

(2) The green APs have a higher price, lower yield and lower cost than ordinary APs: $p_{g}>p_{0}, q_{g}<q_{0}$, and $c_{g}<c_{0}$ (Figure $1 b)$;

(3) The green APs have a higher price, higher yield and higher cost than ordinary APs: $p_{g}>p_{0}, q_{g}>q_{0}$, and $c_{g}>c_{0}$ (Figure $1 c)$;

(4) The green APs have a higher price, higher yield and lower cost than ordinary APs: $p_{g}>p_{0}, q_{g}>q_{0}$, and $c_{g}<c_{0}$ (Figure $1 d$;

(5) The green APs have a lower price, higher yield and higher cost than ordinary APs: $p_{g}<p_{0}, q_{g}>q_{0}$, and $c_{g}>c_{0}$ (Figure $1 \mathrm{e})$;

(6) The green APs have a lower price, higher yield and lower cost than ordinary APs: $p_{g}<p_{0}, q_{g}>q_{0}$, and $c_{g}<c_{0}$ (Figure 1f).

\section{RESEARCH METHODS, DATA SOURCE AND DESCRIPTIVE ANALYSIS}

\subsection{Research methods}

(1) Ordinary least squares (OLS) model

Taking the net mean income per mu $y_{i}$ of farmer households in crop farming as the explained variable, an OLS model was constructed for regression analysis:

$$
y_{i}=a x_{i}+\beta z_{i}+\varepsilon_{i}
$$

where, $z_{i}$ is the key explanatory variable "production of green APs (Yes/No)"; $x_{i}$ is a set of control variables (e.g. household features, production and operation, sales environment, and regional features); $\alpha$ and $\beta$ are regression coefficients; $\varepsilon_{\mathrm{i}}$ is a random error.

(2) Model of treatment effects

For the following reasons, the results of OLS regression may have endogenous problem: On the one hand, the model is endogenous due to measurement errors or the omission of the unobserved variables related to production of green APs (Yes/No); on the other hand, farmer households face the selfselection bias, i.e. fall into the cycle "high-income farmer households produce green APs, and producing green APs increases farmer household income" under the Matthew effect. To correct the endogenous error, the model of treatment effects was introduced:

$$
y_{i}=a x_{i}+\beta z_{i}+\varepsilon_{i}, z_{i}^{*}=\Gamma w_{i}+\mu_{i}
$$

where, $z_{i}$ is the endogenous selection variable "production of green APs (Yes/No)", which depends on the value of $z_{i}^{*} ; y_{i}$ is the net mean income per mu of farmer households in crop farming; $x_{i}$ are the control variables that affect the value of $y_{i}$, which mitigate the endogenous problem arising from the omission of important explanatory variables; $\alpha$ and $\beta$ are regression coefficients; $\varepsilon_{\mathrm{i}}$ is a random error.

The model of treatment effects was implemented in two phases:

In phase 1 , the production equation of $z_{i}^{*}$ was established as formula (5), and coupled with the probit model to identify the factors affecting the green APs production among farmer households.

$$
P\left(Z_{i}=1 \mid x_{1}, x_{2}, \cdots, x_{i}\right)=\Phi\left(\beta_{0}+\beta_{1} x_{1}+\beta_{2} x_{2}+\cdots+\beta_{i} x_{i}\right)
$$

After measuring the inverse Mills ratio $(\lambda)$ of each variable, the self-selection bias was estimated by:

$$
\lambda_{i}=\left\{\begin{array}{l}
\phi\left(\hat{\beta} x_{i}\right) / \Phi\left(\hat{\beta} x_{i}\right), z_{i}=1 \\
-\phi\left(\hat{\beta} x_{i}\right) /\left\{1-\Phi\left(\hat{\beta} x_{i}\right)\right\}, z_{i}=0
\end{array}\right.
$$

where, $\varphi(\mathrm{x})$ and $\phi(x)$ are the cumulative distribution function and probability density function of standard normal distribution, respectively; $x_{i}$ are the control variables that affect green APs production among farmer households; $\beta_{i}$ is the regression coefficient; $\beta_{0}$ is a constant term; $\hat{\beta}$ is the estimated value of $\beta$ in formula (5).

In phase 2 , the corrected self-selection bias $\lambda$ was introduced to formula (4) as an independent variable to construct a new regression equation (7), which obtains unbiased coefficient estimate $[20,21]$ through estimation.

$$
y_{2 i}=\beta z_{i}+\gamma \lambda_{i}+\alpha x_{i}+\varepsilon_{i}
$$

where, $y_{2 i}$ is the net mean income of farmer households in crop farming; $z_{i}$ is the prediction result of production of green APs (Yes/No); $\lambda_{i}$ is the indicator of the presence/absence of endogenous selection bias; $x_{i}$ are the control variables that affect the farmer household income, which are introduced to solve the endogenous problem; $\beta, \gamma$ and $\alpha$ are regression coefficients; $\varepsilon_{i}$ is a random error.

\subsection{Data source}

The research data were collected through a questionnaire survey of farmer households from January to February 2018. To select representative samples, the survey area was determined based on the administrative divisions and the number of certified green APs in the IMAR. The area covers six prefectural administrative regions, namely, Hulunbuir, 
Xing'an and Tongliao in the east, Hohhot in the center, as well as Baotou and Ordos in the west. The six regions are the main producers of green APs in the IMAR, producing nearly $60 \%$ of certified green APs in the IMAR.

The farmer households were randomly surveyed by field visits. First, 1 to 3 counties/banners was selected from each city/league. Then, 2 towns/townships were chosen from every selected county/banner. Finally, several farmer households were randomly selected from each village in the selected towns/townships. The number of farmer households being surveyed in each village was proportional to the total number of villagers. In the end, $223(99.11 \%)$ effective questionnaires were returned, including 126 from farmer households that produce green APs. The survey area and sample distribution are illustrated in Table 1 below.

Table 1. The survey area and sample distribution

\begin{tabular}{cccc}
\hline Region & City/league & $\begin{array}{c}\text { Number of } \\
\text { households }\end{array}$ & $\begin{array}{c}\text { Proportion } \\
(\mathbf{\%})\end{array}$ \\
\hline \multirow{3}{*}{ Eastern region } & Hulunbuir & 17 & 27.42 \\
& Xing'an & 12 & 19.35 \\
& Tongliao & 33 & 53.23 \\
Subtotal & & 62 & 27.80 \\
\hline Central and & Huhhot & 106 & 65.84 \\
western & Baotou & 5 & 3.11 \\
regions & Erdos & 50 & 31.05 \\
Subtotal & & 161 & 72.20 \\
\hline Grand total & & 223 & 100 \\
\hline
\end{tabular}

Data source: Questionnaire survey on farmer households

\subsection{Correlation analysis}

The IMAR is an important food production region in China. From the typical food crops in the IMAR, this paper selects five APs that feature rapid development of green production to examine the impact of green APs production on net mean income per mu of farmer households. The five APs are rice, millet, black bean, red millet and cowpea. Based on the survey data, it is learned that green APs differ greatly from ordinary APs in net mean cost, yield, price and net mean income per mu. As shown in Table 2, green rice is more expensive, less productive and more costly than ordinary rice, creating an additional benefit of 536.21yuan/mu; green millet is more expensive, less productive and less costly than ordinary millet, creating an additional benefit of $451.49 \mathrm{yuan} / \mathrm{mu}$; green black bean is more expensive, more productive and more costly than ordinary black bean, creating an additional benefit of 954 yuan/mu; green red millet is more expensive, more productive and more costly than ordinary red millet, creating an additional benefit of 155.16 yuan/mu; green cowpea is more expensive, more productive and less costly than ordinary cowpea, creating an additional benefit of 523.11 yuan.

The descriptive results confirm that green APs production can indeed increase farmer household income, which agrees with four conditions in the theoretical analysis. The production of green rice and that of millet satisfy conditions 1 and 2, respectively; the production of green black bean and that of green red millet both satisfy condition 3 ; the production of green cowpea satisfies condition 4 . The correlation analysis verifies the results of theoretical analysis.

Table 2. Comparison between green and ordinary APs in net mean cost, yield, price and net mean income per mu

\begin{tabular}{|c|c|c|c|c|c|c|c|c|c|c|}
\hline \multirow[b]{2}{*}{ APs } & \multirow[b]{2}{*}{ Type } & \multicolumn{5}{|c|}{ Production cost (yuan/mu) } & \multicolumn{3}{|c|}{ Production benefit (yuan/mu) } & \multirow{2}{*}{$\begin{array}{l}\text { Net income } \\
\text { (yuan/mu) }\end{array}$} \\
\hline & & Fertilizer & Pesticide & Labor & Others & Total & $\begin{array}{c}\text { Yield } \\
(0.5 \mathrm{~kg} / \mathrm{mu})\end{array}$ & Price (yuan/0.5kg) & Total & \\
\hline \multirow{2}{*}{ Rice } & Green & 154.04 & 8.17 & 73.25 & 478.25 & 713.71 & 494.46 & 4.33 & $2,141.01$ & $1,427.30$ \\
\hline & Ordinary & 156.75 & 53.18 & 80.53 & 245.46 & 535.92 & 648.64 & 2.20 & $1,427.01$ & 891.09 \\
\hline \multirow{2}{*}{ Millet } & Green & 0 & 0.33 & 4.57 & 83.11 & 88.01 & 462.86 & 3.51 & $1,624.64$ & $1,536.63$ \\
\hline & Ordinary & 0 & 9.36 & 12.99 & 152.50 & 174.85 & 477.27 & 2.64 & $1,259.99$ & $1,085.14$ \\
\hline \multirow{4}{*}{$\begin{array}{c}\text { Black } \\
\text { bean } \\
\text { Red } \\
\text { millet }\end{array}$} & Green & 36.67 & 0 & 0 & 53.33 & 90 & 240 & 5 & 1,200 & 1,110 \\
\hline & Ordinary & 20 & 20 & 0 & 34 & 74 & 100 & 2.30 & 230 & 156 \\
\hline & Green & 126 & 0 & 0 & 49.94 & 175.94 & 340 & 1.72 & 584.80 & 408.86 \\
\hline & Ordinary & 66.67 & 0 & 13.33 & 64 & 144 & 323.33 & 1.23 & 397.70 & 253.70 \\
\hline \multirow{2}{*}{ Cowpea } & Green & 50 & 0 & 0 & 10 & 60 & 200 & 3.80 & 760 & 700 \\
\hline & Ordinary & 65.33 & 22.12 & 15.49 & 56.44 & 159.38 & 161.67 & 2.08 & 336.27 & 176.89 \\
\hline
\end{tabular}

Note: In the Production cost column, Fertilizer, Pesticide and Labor are the three inputs that differ significantly between the production of green APs and that of ordinary APs; Others include irrigation, weeding, filming, machinery, and seeds.

\section{EMPIRICAL ANALYSIS}

The correlation analysis demonstrates that green APs production can increase farmer household income. However, this conclusion is not rigorous enough, for the influence of other variables (e.g. household features, production and operation, sales environment, and regional feature) was not controlled. To solve the problem, this section empirically verifies the impact of green APs production on net mean income of green APs per mu of farmer households in crop farming.

\subsection{Variable selection and description}

(1) Explained variable
How to increase farmer income has long been the top priority of agricultural and rural work in China. One of the key metrics of farmer household income is the income of crop farming, especially the net mean income per mu. Therefore, the net mean income per mu of farmer households in crop farming was taken as the explained variable. According to the Compilation of Cost-Benefit Data on Agricultural Products in China, the net mean income per mu was calculated as follows:

Net mean income per mu of farmer households in crop farming $=$ yield per mu $\times$ price per $0.5 \mathrm{~kg}-$ seed cost per mu fertilizer cost per mu - irrigation cost per mu - weeding cost per mu - pesticide cost per mu - filming cost per mu machinery cost per mu - labor cost per mu- rental expense per $\mathrm{mu}+$ rental income per mu. 
(2) Key explanatory variable

Green APs can support and benefit farmers. China is encouraging the production of green APs, aiming to increase the income of farmer households in crop farming. According to the principles of high quality and good price, green APs play an important role in increasing the income of farmer households in crop farming. Hence, this research treats production of green APs (Yes/No) as the key explanatory variable, and explores its realistic impact and influence mechanism on net mean income per mu of farmer households in crop farming.

(3) Control variables

Relevant literature has shown that farmer household income is influenced by household features [22-24], production and operation [25], sales environment [26], and regional features [27]. Thus, the authors selected 14 variables (Table 3) as the control variables that affect farmer household income. Besides, four variables related to production decision (i.e. nonagricultural income, awareness of green APs, planting years of green APs, and number of participations in green APs production and certification trainings) were deleted from the income equation in the model of treatment effects, and four variables related to farmer household income (i.e. years of farming, number of agricultural machinery, loan amount, frequent checking of online information on APs sales (Yes/No) were added to that equation. The other variables were not adjusted. All variables are defined and explained in Table 3 below.

Table 3. Definitions and descriptions of all variables

\begin{tabular}{|c|c|c|c|c|c|c|}
\hline \multicolumn{2}{|c|}{ Variables } & Definition and value & Mean & $\begin{array}{l}\text { Standard } \\
\text { deviation }\end{array}$ & Min. & Max. \\
\hline \multicolumn{7}{|c|}{ Explained variable } \\
\hline \multicolumn{2}{|c|}{ Net mean income per mu in crop farming } & $\begin{array}{l}\text { Net mean income per mu of farmer } \\
\text { households in crop farming (RMB } \\
10,000 \text { yuan) }\end{array}$ & 0.08 & 0.26 & -0.60 & 1.31 \\
\hline \multicolumn{2}{|c|}{ Key explanatory variable } & & & & & \\
\hline \multicolumn{2}{|c|}{ Production of green APs (Yes/No) } & Yes $=1 ; \mathrm{No}=0$ & 0.57 & 0.50 & 0 & 1 \\
\hline \multicolumn{7}{|c|}{ Control variables: } \\
\hline \multirow{5}{*}{$\begin{array}{l}\text { Household } \\
\text { features }\end{array}$} & Age & Age (year) & 53.36 & 9.91 & 22 & 74 \\
\hline & Years of education & Years of education (year) & 6.11 & 3.05 & 0 & 15 \\
\hline & Years of farming & Years spent in crop farming (year) & 32.30 & 12.21 & 2 & 54 \\
\hline & Cadre in the family (Yes/No) & $\mathrm{Yes}=1 ; \mathrm{No}=0$ & 0.13 & 0.34 & 0 & 1 \\
\hline & Proportion of laborers & $\begin{array}{l}\text { Proportion of laborers in the total } \\
\text { number of household members (\%) }\end{array}$ & 74.50 & 24.52 & 20 & 100 \\
\hline \multirow{3}{*}{$\begin{array}{l}\text { Production } \\
\text { and operation }\end{array}$} & Planting scale & Planting area $(\mathrm{mu})$ & 51.36 & 141.95 & 1 & 1500 \\
\hline & Number of agricultural machinery & $\begin{array}{l}\text { The number of agricultural machinery } \\
\text { owned by the household (each) }\end{array}$ & 1.16 & 2.30 & 0 & 20 \\
\hline & Loan amount & $\begin{array}{l}\text { The actual amount of loan of the } \\
\text { household }\left(10^{4} \text { yuan }\right)\end{array}$ & 2.95 & 7.79 & 0 & 90 \\
\hline $\begin{array}{l}\text { Sales } \\
\text { environment }\end{array}$ & $\begin{array}{l}\text { Frequent checking of online } \\
\text { information on APs sales } \\
(\text { Yes/No) }\end{array}$ & $\mathrm{Yes}=1 ; \mathrm{No}=0$ & 0.20 & 0.40 & 0 & 1 \\
\hline \multirow[t]{3}{*}{$\begin{array}{l}\text { Regional } \\
\text { features }\end{array}$} & Region & $\begin{array}{c}\text { Eastern region }=0 ; \text { Central and western } \\
\text { regions }=1\end{array}$ & 0.72 & 0.45 & 0 & 1 \\
\hline & Non-agricultural income & $\begin{array}{l}\text { Income from sources other than crop } \\
\text { farming }\left(10^{4} \text { yuan }\right)\end{array}$ & 2.10 & 3.43 & 0.01 & 28.49 \\
\hline & Awareness of green APs & $\begin{array}{l}\text { Cognition score of the relevant } \\
\text { knowledge on green APs production } \\
\text { (point) }\end{array}$ & 2.53 & 1.54 & 0 & 4 \\
\hline \multirow{2}{*}{ Others } & Planting years of green APs & $\begin{array}{c}\text { Years spent in planting green APs } \\
\text { (year) }\end{array}$ & 2.35 & 2.88 & 0 & 12 \\
\hline & $\begin{array}{l}\text { Number of participations in green } \\
\text { APs production and certification } \\
\text { trainings }\end{array}$ & $\begin{array}{c}\text { Number of participations in green APs } \\
\text { production and certification trainings } \\
\text { (each) }\end{array}$ & 1.57 & 3.26 & 0 & 30 \\
\hline
\end{tabular}

Note: Non-agricultural income includes livestock income, wage income, part-time income, property income and transfer income.

\subsection{Regression results and robustness test}

(1) Regression results and analysis

The net mean income per mu of farmer households in crop farming was regressed by the OLS model and the model of treatment effects, respectively. The regression results are listed in Table 4 below. For OLS results, the coefficient of determination $\left(\mathrm{R}^{2}\right)$ was 0.605 , indicating that the OLS model has a low goodness-of-fit. For the model of treatment effects, the $\mathrm{p}$-value for the erogeneity of production equation was 0.015 , and the p-value for the independence of the equations in two phases was 0.000 . Both results show that the production equation is correlated with the income equation, an evidence of the endogenous problem in green APs production. Since the OLS cannot solve the endogenous problem, the results of the model of treatment effects were analyzed as follows:

1) Green APs production can increase farmer household income. The key explanatory variable "production of green APs (Yes/No)" had a positive impact on the net mean income per mu of farmer households in crop farming at the significance level of $1 \%$. This means green APs production obviously promotes farmer household income. The high quality of green APs deserves a good price. The price advantage brings additional benefit to farmer households, promoting their income. Thus, our hypothesis $\mathrm{H}$ was fully verified. 
2) Among the control variables, years of education, planting scale, number of agricultural machinery, loan amount, frequent checking of online information on APs sales (Yes/No), and region had positive impacts on the net mean income per mu of farmer households in crop farming at the significance level of $1 \%$. The results show that farmer households have a high net mean income per mu in crop farming, if they live in the central or western region, frequently check online information on APs sales, loan a huge sum of money, own lots of agricultural machinery, plant a wide area, and receive many years of education.
By contrast, years of labor had a significant negative impact on net mean income per mu of farmer households in crop farming at the significance level of $5 \%$, indicating that households that have long been engaged in farming tend to earn a low net income. The conclusion echoes with the survey data: the senior farmers being surveyed are relatively old and less educated; their net mean income per mu in crop farming is relatively low, due to the decrease of stamina and energy, and the poor access to information on production, operation and sales.

Table 4. Regression results of empirical models

\begin{tabular}{|c|c|c|c|}
\hline \multirow{2}{*}{ Variables } & \multirow{2}{*}{$\begin{array}{c}\text { OLS model } \\
\text { Income equation }\end{array}$} & \multicolumn{2}{|c|}{ Model of treatment effects } \\
\hline & & Income equation & Production equation \\
\hline Production of green APs (Yes/No) & $0.0565^{* * *}(0.0264)$ & $0.0906^{* * * *}(0.0297)$ & - \\
\hline Age & $0.0034(0.0022)$ & $0.0034(0.0021)$ & $0.0240(0.0203)$ \\
\hline Years of education & $0.0142^{* * * *}(0.0042)$ & $0.0124^{* * * *}(0.0042)$ & $0.1980^{* * * *}(0.0716)$ \\
\hline Cadre in the family (Yes/No) & $-0.0293(0.0352)$ & $-0.0351(0.0345)$ & $0.2211(0.5102)$ \\
\hline Proportion of laborers & $0.0002(0.0005)$ & $0.0001(0.0005)$ & $0.0051(0.0078)$ \\
\hline Planting scale & $0.0005^{* * * *}(0.0001)$ & $0.0005^{* * * *}(0.0001)$ & $0.0064^{* * * *}(0.0024)$ \\
\hline Years of farming & $-0.0040^{* *}(0.0017)$ & $-0.0041^{* *}(0.0017)$ & - \\
\hline Number of agricultural machinery & $0.0293^{* * * *}(0.0063)$ & $0.0284^{* * * *}(0.0061)$ & - \\
\hline Loan amount & $0.0086^{* * * *}(0.0019)$ & $0.0089^{* * * *}(0.0019)$ & - \\
\hline $\begin{array}{l}\text { Frequent checking of online information on } \\
\text { APs sales (Yes/No) }\end{array}$ & $0.0972^{* * * *}(0.0347)$ & $0.0931^{* * * *}(0.0334)$ & - \\
\hline Non-agricultural income & - & - & $0.4315^{* * * *}(0.1520)$ \\
\hline Awareness of green APs & - & - & $0.4292^{* * * *}(0.1379)$ \\
\hline Planting years of green APs & - & - & $0.5903^{* * * *}(0.0899)$ \\
\hline $\begin{array}{l}\text { Number of participations in green APs } \\
\text { production and certification trainings }\end{array}$ & - & - & $0.2897^{* * * *}(0.1090)$ \\
\hline Region & $0.1592^{* * * *}(0.0307)$ & $0.1464^{* * * *}(0.0305)$ & $0.1727(0.4350)$ \\
\hline Constant term & $-0.2630^{\text {**** }}(0.0845)$ & $-0.2503^{* * * *}(0.0824)$ & $-6.0034(1.5283)$ \\
\hline P-value & 0.0000 & \multicolumn{2}{|c|}{0.0000} \\
\hline $\mathrm{R}^{2}$ & 0.6052 & \multicolumn{2}{|c|}{-} \\
\hline$\lambda$ & - & \multicolumn{2}{|c|}{$-0.0695^{* *}(0.0286)$} \\
\hline Wald chi2 & - & \multicolumn{2}{|c|}{355.1500} \\
\hline Observed value & 223 & \multicolumn{2}{|c|}{223} \\
\hline
\end{tabular}

Note: The bracketed figures are standard deviations; $* * *$ and $* *$ means the corresponding variable passes the significance test at $1 \%$ and $5 \%$, respectively.

\section{(2) Robustness test}

The samples were grouped by planting scale for regression analysis, aiming to eliminate the impact of sample difference in planting scale on results stability. Specifically, a farmer household was defined as a small household if the planting area is smaller than $10 \mathrm{mu}$, as a medium household if the planting area falls in [10mu, 40mu), and as a large household if the planting area is greater than $40 \mathrm{mu}$. According to the robustness test results (Table 5), green APs production had a significant positive impact on the net mean income in crop farming, for households on any scale. Therefore, the results of the empirical models must be robust and credible.

Table 5. Results of robustness test

\begin{tabular}{lccc}
\hline \multicolumn{1}{c}{ Variables } & Small households & Medium households & Large households \\
\hline Key explanatory variable: & $0.1879^{* * * *}(0.0590)$ & $0.1009^{* * *}(0.0333)$ & $0.2059^{* *}(0.0996)$ \\
Production of green APs (Yes/No) & & & \\
Other explanatory variables: & Controlled & Controlled & Controlled \\
Control variables & $0.0352(0.1939)$ & $-0.3308(0.1135)$ & $-0.5732(0.1872)$ \\
Constant term & 0.0000 & 0.0000 & 0.0000 \\
P-value & 60 & 93 & 70 \\
Observed value & & 90 & \\
\hline
\end{tabular}

Note: The bracketed figures are standard deviations; $* * *$ and $* *$ means the corresponding variable passes the significance test at $1 \%$ and $5 \%$, respectively.

\section{CONCLUSIONS}

The previous studies have shown that green APs production could increase the net mean income of farmer households in crop farming. However, simple comparisons cannot disclose the actual impact of green APs production on farmer household income. To solve the problem, this paper measures the said impact empirically against the survey data collected from the IMAR. Two conclusions were drawn from the empirical analysis: (1) Production of green APs had a positive 
impact on the net mean income per mu of farmer households in crop farming, indicating that green APs production obviously promotes farmer household income. (2) The net mean income per mu of farmer households in crop farming is also greatly influenced by other control variables, such as years of education, planting scale, years of farming, number of agricultural machinery, loan amount, frequent checking of online information on APs sales (Yes/No) and region. Among them, years of farming greatly suppresses the net mean income per mu of farmer households in crop farming.

Based on these conclusions, the authors made the following suggestions on agricultural policies: (1) Make continued efforts to promote green APs production. Being the visible hand, the government should nurture and enhance the awareness of green APs production among farmer households through publicity and trainings. More incentives should be given to farmer households engaging in green APs production, such as distributing organic fertilizer and mulching film, reducing the cost of green APs certification, and giving priority to them in agricultural-related projects, funds and policies. In this way, more farmer households will be encouraged to produce green APs, improving the quality and benefits of agriculture. (2) Pay attention to the impact of other factors on farmer household income. How much a farmer household can earn through production hinges on the features of the household. The further of green APs production relies on the well-educated farmer households in the central and western regions, which manage a large farm, master agricultural technologies, and have a good credit score. Therefore, the government should stimulate these farmer households to produce green APs, and improve the agricultural literacy of farmer households through legislation, subsidies, and skill guidance. The influencing factors of green APs production should be well coordinated to enable farmer households to make more profit.

\section{ACKNOWLEDGMENT}

This work is supported by the Planning Office of Social Sciences, Inner Mongolia Autonomous Region, China (Grant No.: 2018ZGH006 and 2018ZDA004).

\section{REFERENCES}

[1] Yu, F.W. (2018). An analysis of the reasons, core and countermeasures of agricultural green development in the new era. Chinese Rural Economy, 5: 19-34.

[2] Yu, X.H., Gao, Z.F., Zeng, Y.C. (2014). Willingness to pay for the "Green Food" in China. Food Policy, 45: 8087. https://doi.org/10.1016/j.foodpol.2014.01.003

[3] Liu, R.F., Gao, Z.F., Yan, G.A., Ma, H.Y. (2018). Why should we protect the interests of "Green Food" certified product growers? Evidence from Kiwifruit Production in $\begin{array}{lll}\text { China. } & \text { Sustainability, } & \text { 12(10): }\end{array}$ https://doi.org/10.3390/su10124797

[4] Ponisio, L.C., M'Gonigle, L.K., Mace, K.C., Palomino, J., Valpine, P.D., Kremen, C. (2015). Diversification practices reduce organic to conventional yield gap. Proceedings: Biological Sciences, 282(1799): 1-7. https://doi.org/10.1098/rspb.2014.1396

[5] Crowder, D.W., Reganold, J.P. (2015). Financial competitiveness of organic agriculture on a global scale.
Proceedings of the National Academy of Sciences, 112(24): 7611-7616

https://doi .org/10.1073/pnas.1423674112

[6] Ibanez, M., Blackman, A. (2016). Is eco-certification a win-win for developing country agriculture? Organic coffee certification in Colombia. World Development, 82: 14-27. https://doi.org/10.1016/j.worlddev.2016.01.004

[7] Haggar, J., Soto, G., Casanoves, F., Virginio, E.D. (2017) Environmental-economic benefits and trade-offs on sustainably certified coffee farms. Ecological Indicators, 79:

330-337.

https://doi.org/10.1016/j.ecolind.2017.04.023

[8] Beltran-Esteve, M., Reig-Martinez, E., Estruch-Guitart, V. (2017). Assessing eco-efficiency: A metafrontier directional distance function approach using life cycle analysis. Environmental Impact Assessment Review, 63: 116-127. https://doi.org/10.1016//j.eiar. 2017.01.001

[9] Khanal, A.R., Mishra, S.K., Honey, U. (2018). Certified organic food production, financial performance, and farm size: An unconditional quantile regression approach. Land Use Policy, 78: 367-376. https://doi.org/10.1016/j.landusepol.2018.07.012

[10] Mishra, A.K., Kumar, A., Joshi, P.K., D'Souza, A., Tripathi, G. (2018). How can organic rice be a boon to smallholders? Evidence from contract farming in India. Food Policy, 75: 147-157. https://doi.org/10.1016/j.foodpol.2018.01.007

[11] Krause, J., Machek, O. (2018). A comparative analysis of organic and conventional farmers in the Czech Republic. Agricultural Economics: The Journal of the International Association of Agricultural Economists, 61(1): 1-8. https://doi.org/10.17221/161/2016-AGRICECON

[12] Ayuya, O.I. (2019). Organic certified production systems and household income: micro level evidence of heterogeneous treatment effects. Organic Agriculture, 9(4): 417-433. https://doi.org/10.1007/s13165-0180236-8

[13] Karunakaran, N., Sadiq, M.S. (2019). Socio economic aspect of organic farming practices for improving farmer's income in some locations of Kerala, India. Bangladesh Journal of Agricultural Research, 44(3): 401408. https://doi.org/10.3329/bjar.v44i3.43474

[14] Vasile, A.J., Popescu, C., Ion, R.A., Dobre, L. (2015). From conventional to organic in Romanian agriculture Impact assessment of a land use changing paradigm. Land Use Policy, 46: 258-266. https://doi.org/10.1016/j.landusepol.2015.02.012

[15] Bett, E.K., Ayieko, D.M. (2017). Economic potential for conversion to organic farming: A net present value analysis in the East Mau Catchment, Nakuru, Kenya. Environment, Development and Sustainability, 19(4): 119. https://doi.org/10.1007/s10668-016-9800-0

[16] Qiao, Y.H., Martin, F., Cook, S., He, X.Q., Halberg, N., Scott, S., Pan, X.H. (2018). Certified Organic Agriculture as an alternative livelihood strategy for small-scale farmers in China: A case study in Wanzai county, Jiangxi Province. Ecological Economics, 145: 301-307. https://doi.org/10.1016/j.ecolecon.2017.10.025

[17] Doanh, N.K., Thuong, N.T.T., Heo, Y. (2018). Impact of conversion to organic tea cultivation on household income in the mountainous areas of Northern Vietnam. Sustainability, 10(12): 1-21. https://doi.org/10.3390/su10124475

[18] Li, K. (2019). Presentation contents of press conference 
about green and high quality development of agriculture and animal husbandry in Inner Mongolia Autonomous Region. Government Network in Inner Mongolia. http://www.nmg.gov.cn/art/2019/12/23/art_1972_29218 2.html.

[19] Hu, Q.F., Xu, B. (2019). Differential game analysis of optimal strategies and cooperation in omni-channel organic agricultural supply chain. Sustainability, 11(3): 1-34. https://doi.org/10. 3390/su11030848

[20] Zhang, X.G., Zhao, Y.F. (2016). Could farmers' income be stabilized by livestock insurance? - Based on the empirical analysis of Baotou in Inner Mongolia. Journal of Arid Land Resources and Environment, 30(10): 40-46. https://doi.org/10.13448/j.cnki.jalre.2016.314

[21] Gan, H.Q., Zheng, C.Y., Cui, H.T. (2019). A two-stage model for capacity planning of centralized charging station and ordered discharging. Journal of Intelligent \& Fuzzy Systems, 37(4): 1-10. https://doi.org/10.3233/JIFS-179321

[22] Mishra, A.K., Kumar, A., Joshi, P.K., D'souza, A. (2016). Impact of contracts in high yielding varieties seed production on profits and yield: The case of Nepal. Food Policy, 62: $110-121$ https://doi.org/10.1016/j.foodpol.2016.05.005

[23] Xu, C.H., Yu, J. (2020). The income effect of land transfer under the background of "division of three
rights"-Based on the survey of farmers in 10 counties of 3 major grain-producing provinces. Journal of Huazhong Agricultural University (Social Sciences Edition), 1: 1827 , 162 . https://doi.org/10.13300/j.cnki.hnwkxb.2020.01.003

[24] Chuang, Y. (2019). Climate variability, rainfall shocks, and farmers' income diversification in India. Economics Letters, 174: 55-61. https://doi.org/10.1016/j.econlet.2018. 10. 015

[25] Liu, J.W. (2017). The impact of farmers' specialized cooperatives on rural poor households' income: evidences from Shandong and Guizhou provinces. Chinese Rural Economy, 2: 44-55.

[26] Li, X., Han, Y.J., Wang, Y. (2019). Analysis on the influencing factors of farmers'income in main grain producing areas-Based on the household survey data in Hebei, Shandong and Henan. East China Economic Management, 33(10): 92-100. https://doi.org/10.19629/j.cnki.34-1014/ f.181205024

[27] Peng, W.H., Huang, Z.H. (2017). Can cooperatives help to increase farmers' income- Analysis based on endogenous switching regression model and cooperatives' service functionality. Journal of Northwest A\&F University (Social Science Edition), 17(4): 57-66. https://doi.org/10.13968/j.cnki.1009-9107.2017.04.08 